\title{
Paulo Freire, comunicação e democracia
}

Roseli Figaro

Professora livre-docente do Programa de Pós-graduação em Ciências da Comunicação da ECAUSP, editora da Revista Comunicação Ė Educação e coordenadora do Centro de Pesquisa em Comunicação e Trabalho (CPCT-ECA/USP).

E-mail: figaro@uol.com.br

Resumo: O objetivo da primeira parte deste artigo é retomar a discussão sobre a base conceitual e a referência teórica freireana que orientam a inter-relação comunicação/ educação ou, o neologismo, educomunicação. Sobretudo, vamos nos pautar pelas contribuições do estudo de Venício A. Lima sobre as ideias de Paulo Freire. Na segunda parte, cumprimos o objetivo de apresentar os artigos e os autores da presente edição de Comunicação \& Educação.

Palavras-chave: comunicação, educação, educomunicação, alfabetização de adultos, Paulo Freire, Brasil
Abstract: The objective of the first part of this article is to resume the discussion on the conceptual basis and Freire's theoretical framework underlying the interrelationship communication/education or the neologism, educational communication. Above all, let us be guided by Venício A. de Lima study about contributions on Paulo Freire's ideas. In the second part, we fulfill the objective of presenting the articles and the authors of this edition of Communication \& Education.

Keywords: communication, education, educational communication, adult literacy, Paulo Freire, Brazil

\section{INTRODUÇÃO}

Os apelos para as tecnologias na sala de aula não são novos. Já em 1934 Roquette Pinto fundava a Rádio Escola Municipal do Rio de Janeiro. Os cursos à distância por correspondência formaram muitos técnicos pelo Brasil afora e, no mundo, cresceram, principalmente, na França e na Inglaterra, com o desenvolvimento dos correios. O áudio e o vídeo também foram peças chave, por meio de fitas de vídeo cassete, nos anos de 1970 e 1980. Essas inovações foram demandadas pela necessidade do letramento em diferentes áreas do conhecimento, principalmente, nas disciplinas básicas das Ciências Humanas, Biológicas e Exatas, devido ao tipo de organização da economia e da vida nos marcos das cidades modernas.

A necessidade de força de trabalho qualificada para o desempenho em fábricas e escritórios colocou para o Estado brasileiro o desafio da alfabetização e da formação profissional, sobretudo, para a parcela de mais de $50 \%$ da população analfabeta até meados dos anos de 1950. Os dados que estão no Quadro I, cuja fonte é o IBGE - Instituto Brasileiro de Geografia e Estatística, 
demonstram como no período de 1940 a 2010 as taxas do analfabetismo foram caindo muito lentamente. Mesmo na atualidade, a persistência do analfabetismo desafia programas governamentais e mantém-se entre adultos e nas Regiões brasileiras mais pobres.

\section{Quadro I}

Taxa de analfabetismo das pessoas de 15 anos ou mais de idade no Brasil - 1940/2010

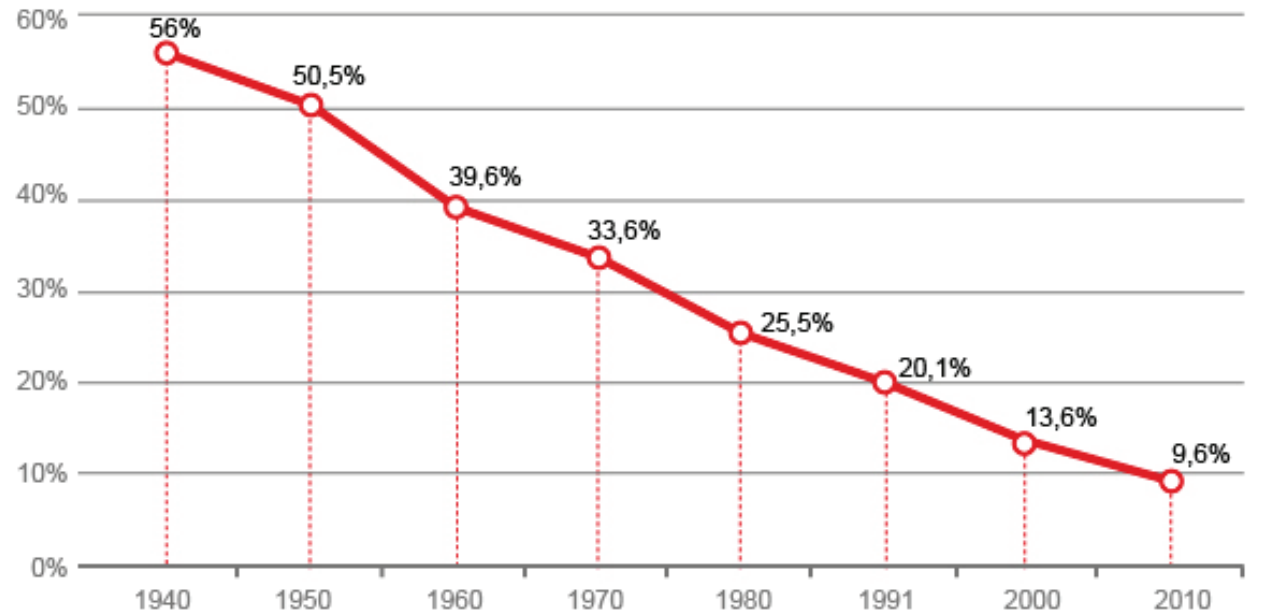

7 .com.br

Quadro II

\section{Evolução das taxas de analfabetismo por região}

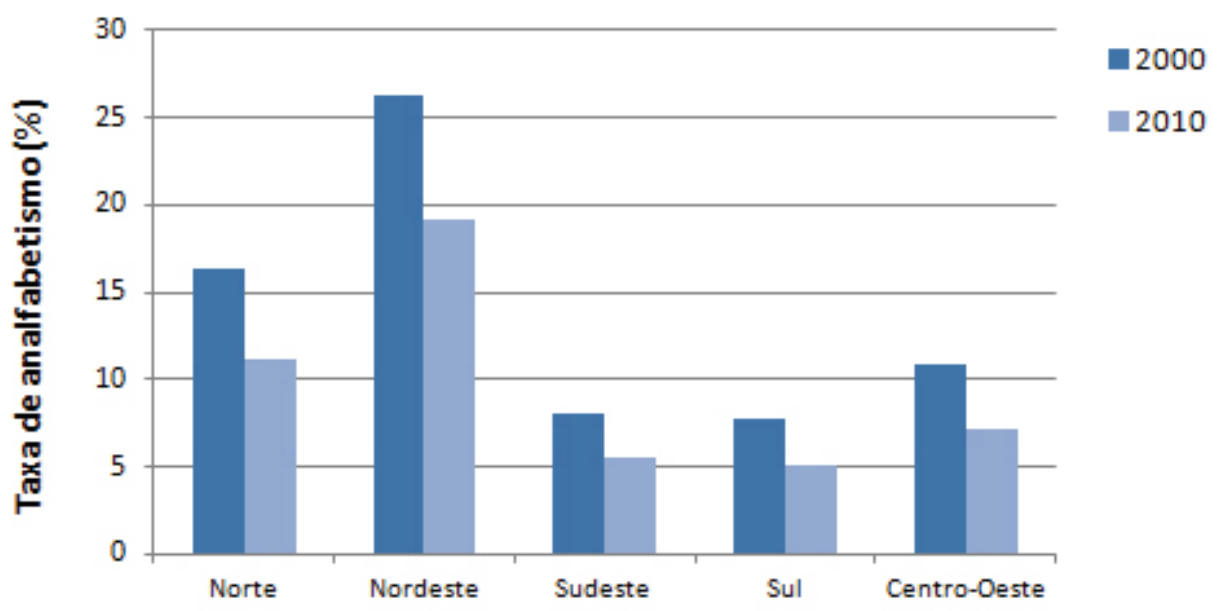

Fonte: IBGE, Censo Demográfico 2010, Indicadores sociais municipais 
No Quadro I chama nossa atenção o dado de que entre as décadas de 1950 e 1960, o Brasil avançou consideravelmente na queda do analfabetismo, passando de $50,5 \%$ para $39,6 \%$ da população. É a primeira vez que se registra queda tão acentuada em apenas dez anos. Provavelmente, os motivos que contribuíram para essa expressiva queda foram a redemocratização do país, o êxodo do campo para a cidade, a industrialização, os programas de alfabetização e a maior participação da população na vida política do país. É notório também, como indicam os dados do Quadro II, a redução dos índices de analfabetismo, entre os anos 2000-2010, mesmo nas Regiões mais pobres do país. Na Região Sul, os dados indicam em torno de $5 \%$ de analfabetos em idade adulta.

Os dados mostram a relevância dos períodos políticos democráticos no Brasil para que a conquista do direito ao letramento e à escola se ampliem efetivamente para o conjunto da população. Essa era a tese principal que dá origem à prática pedagógica de Paulo Freire.

\section{PAULO FREIRE E A ALFABETIZAÇÃO DE ADULTOS}

É nesse contexto que Paulo Freire ganha destaque. Ele próprio, cujo letramento se deu em casa, foi para a escola somente perto dos 15 anos de idade, depois estudou Direito, mas, desde os 23 anos, torna-se professor no curso secundário. Com formação católica, milita entre os progressistas na Ação Católica e é um dos fundadores do Movimento de Cultura Popular no Recife. Nesse período, tem forte engajamento nas formas de organização popular pela emancipação.

Esse seu engajamento é, sobretudo, voltado para a educação. As experiências com a alfabetização de adultos faz com que ele desenvolva uma abordagem que chama de 'processo de conscientização', ou seja, defende que o povo analfabeto e pobre tome consciência de sua condição, de maneira à mobilização política. Seu programa de alfabetização, realizado com sucesso em comunidades pobres do Recife e, especialmente, a experiência realizada em Angicos, RN, com 300 adultos alfabetizados em 45 dias, foi reconhecido pelo então governo democrático de João Goulart, passando a programa oficial do Ministério da Educação em 1963.

Embora e, talvez, exatamente porque obteve bons resultados, a ação do programa de alfabetização de Paulo Freire foi cassada com o golpe civil-militar de 1964. Venício Lima cita o professor Joseph Page, em trecho no qual descreve a invasão do Serviço de Extensão Cultural, dirigido por Freire, da Universidade do Recife:

Uma das primeiras iniciativas do Exército foi invadir a sede do Serviço de Extensão Cultural (SEC), dirigido por Paulo Freire, na Universidade de Recife, e confiscar todo o material utilizado no programa de alfabetização ${ }^{1}$.

Depois da prisão, Paulo Freire segue para o exílio no Chile, país no qual vai escrever uma parte importante de sua obra, frente às experiências que desenvolvera com a alfabetização de camponeses. Extensão ou comunicação será
1. PAGE, Joseph. The revolution that never was: northeast Brazil 19551964. Nova York: Grossman, 1972. Apud LIMA, Venício A. Comunicação e cultura. As ideias de Paulo Freire. 2. ed. rev., Brasília: UnB/Perseu Abramo, 2011. 
uma delas, publicada no Brasil, em 1971, constitui-se em uma das referências importantes sobre a relação intrínseca que ele estabelece entre comunicação e educação. Os cinco anos que permaneceu no Chile foram muito produtivos e resultaram em dois de seus livros mais importantes: Educação como prática de liberdade e Pedagogia do Oprimido.

É nos Estados Unidos, durante o período de dez meses que ministrou cursos em Harvard, que Paulo Freire escreve Ação Cultural para a Liberdade. Em seus escritos, Paulo Freire confirma sua adesão intelectual e prática à causa das populações pobres e excluídas do letramento em idade ideal. É também em seus livros que estão entrelaçados o compromisso com a reflexão teórico-metodológica e a prática para a emancipação.

Os conceitos que dão base ao seu pensamento são, sobretudo, aqueles vinculados ao reconhecimento da importância da experiência e da cultura populares para a compreensão do homem comum, como sujeito, ser de vontade e capaz de transformação. Define o conceito de 'tomada de consciência' como percurso da construção da autonomia e da emancipação, e, coerente com esses pressupostos, defende a concepção de educação como processo de comunicação e prática de liberdade.

\section{COMUNICAÇÃO/EDUCAÇÃO PARA PAULO FREIRE}

Comunicação é, para Paulo Freire, uma característica essencial da humanidade, faz parte da natureza humana. Lima ${ }^{2}$ sintetiza a comunicação para Freire em quatro aspectos: primeiro sua natureza própria e restrita ao ser humano, outros animais não têm a natureza da comunicação humana. Ou seja, a comunicação como realidade existencial e ontológica da natureza humana. A segunda trata da comunicação como diálogo como "compromisso político com a mudança revolucionária na perspectiva dos oprimidos"3. Portanto, a comunicação é relação social contextualizada e histórica. Perspectiva que nos leva ao terceiro aspecto do conceito de comunicação. Ou seja, ela é ação cultural para a liberdade. O quarto aspecto refere-se à comunicação dialógica. Freire entende a comunicação como relação de diálogo que se baseia na relação eu-tu, no processo histórico do contexto de diferentes interesses entre as classes sociais. Portanto, nesse aspecto distancia-se da perspectiva individualista de Martin Buber ${ }^{4}$ (conclamar as pessoas ao amor) à medida que o humanismo radical de Freire está comprometido com o social e o político.

2. LIMA, Venício A. Comunicação e cultura. As ideias de Paulo Freire. 2.ed. rev., Brasília: UnB/ Perseu Abramo, 2011. p.103.

3. Idem.

4. BUBER, Martin. Eu e Tu. São Paulo: Cortez e Moraes, 1977.
Dessa maneira, conforme Venício A. Lima, pode-se afirmar que

[...] a comunicação significa coparticipação dos Sujeitos no ato de pensar, que o objeto de conhecimento não pode se constituir no termo exclusivo do pensamento, mas, de fato, é seu mediador, e que o conhecimento é construído por meio das relações entre os seres humanos e o mundo, Freire está, na verdade, definindo a comunicação como a situação social na qual as pessoas criam conhecimentos juntas, transformando e humanizando o mundo em vez de transmiti-lo, dá-lo ou impô-lo. A comunicação é uma interação entre Sujeitos iguais e criativos ${ }^{5}$. 
Essa compreensão que Paulo Freire tem da comunicação, como relação social, cujo processo de interação coloca os sujeitos em diálogo, mesmo que eles tenham perspectivas diferentes, é a base da democracia e do espírito de cidadania. A educação, para Freire, deriva dessa perspectiva comunicacional e emancipatória, que só se dá de maneira contextualizada e tendo em conta a totalidade social.

\section{CONSIDERAÇÕES PARA REFLETIR}

Muito atuais são as palavras de Paulo Freire. Por meio delas, podemos compreender melhor os grandes desafios que a sociedade brasileira tem pela frente. As novas gerações, cujas vidas estão entrelaçadas pelos gadgets tecnológicos, que podem ou não potencializar a comunicação, carecem conhecer a obra de Paulo Freire.

Por isso, nestes vinte anos de Comunicação Ẽ Educação, temos feito grande esforço para contribuir com a discussão sobre a necessidade de se ampliar a democracia, sobretudo, em relação aos meios de comunicação e a escola. No primeiro número da Revista, a então diretora editorial e fundadora, Maria Aparecida Baccega afirma em seu texto inaugural:

Como diz Paulo Freire, nós vivemos no mundo e com o mundo. E que mundo é esse? É aquele que é trazido até o horizonte de nossa percepção, até o universo de nosso conhecimento. Afinal, não podemos estar "vendo" todos os acontecimentos, em todos os lugares. É preciso que "alguém” os relate para nós ${ }^{6}$.

A autora nos fala de como o "mundo nos chega editado", dos "filtros" institucionais (família, escola, igreja e meios de comunicação) pelos quais o relato do e sobre o mundo nos chega. E nos chama a atenção para um dos pontos básicos de reflexão sobre o espaço fundamental de inter-relação de comunicação e educação. O mundo que chega a todos nós passa por "filtros de edição", os quais existem em torno de interesses, os mais diversos e contraditórios, nomeadamente, interesses econômicos. É fazendo jus a essa carta de fundação da revista Comunicação $\mathcal{E}$ Educação que convidamos nossos leitores a buscar conhecer quais são os "filtros" que estão presentes no "mundo que nos chega editado" e, acompanha este convite, a sugestão da releitura da obra tão fundamental de Paulo Freire.

Passamos a apresentar os artigos e os autores desta edição de Comunicação $\mathcal{E}^{2}$ Educação com a certeza de que esta é nossa contribuição na perspectiva da vitalidade da jovem balzaquiana democracia brasileira.

\section{ARTIGOS NACIONAIS}

São quatro os artigos de autores brasileiros que tratam, cada um a seu modo, dos desafios da comunicação na atualidade. Anna Maria Balogh, em Dalinianas e outras metamorfoses imagéticas, reflete sobre os

6. BACCEGA, Maria Aparecida. Do mundo editado à construção do mundo. Comunicação \& Educação. 1994, n.1, p.7. 
"processos de metamorfose imagética. Obras do pintor catalão Salvador Dalí servem como inspiração para apontar desafiadores processos de transformação da imagem, num amplo leque que vai desde metamorfoses intratextuais até passagens de suportes como foto para pintura, instalação e até mesmo a serialização em objetos de grife".

Jiani Adriana Bonin e Franciele Zarpelon Corrêa discutem, no artigo Práticas educomunicativas no projeto Alunos em Rede - Mídias Escolares e cidadania comunicativa, as práticas no processo de produção radiofônica do projeto Alunos em Rede - Mídias Escolares (AlemRede). O objetivo das autoras é compreender "as potencialidades para o aprendizado e o exercício da cidadania comunicativa vinculada à dimensão cultural”. O projeto foi desenvolvido a partir de oficinas pedagógicas de rádio e mídias com estudantes de escolas municipais de Porto Alegre (RS). A violência escolar em matérias de jornal: um imaginário construído em Belém-PA é o título do artigo de autoria de Livia Sousa da Silva e Kátia Marly Leite Mendonça. Nele as autoras tratam da "pertinência de um estudo que considere a mídia como partícipe da construção de certo imaginário da violência escolar na cidade de Belém e como vetor privilegiado dessas imagens". Elas consideram que hoje há "um grande esforço para a compreensão do fenômeno da violência escolar, talvez seja tempo de considerar seus significados no âmbito da sua veiculação midiática”. Graça Penha Nascimento Rossetto, Rodrigo Carreiro e Maria Paula Almada e Silva, no artigo Organizações Civis na web: desafios e potencialidades na apropriação das plataformas digitais, discutem iniciativas de apropriação "das plataformas digitais para ampliar espaços de participação e cumprir objetivos de ação". Os autores cumprem este objetivo fazendo um estudo exploratório na rede social com o Cidade Democrática, ferramenta colaborativa, que disponibiliza instrumentos de ação para os cidadãos apontarem problemas bem como divulgarem suas opiniões e sugestões acerca de assuntos públicos.

\section{ARTIGOS INTERNACIONAIS}

O professor mexicano Javier González García, em seu artigo Critérios para a elaboração de materiais multimídia, faz revisão dos pontos coincidentes entre as Tecnologias de Informação e Comunicação (TIC) e as teorias da aprendizagem, para propor discussão sobre os conceitos de interatividade e de multimodalidade, visando à compreensão e importância deles no âmbito da criação de uma página educativa na internet. Já Teresa Quiroz Velasco, diretora do Instituto de Investigação Científica da Universidade de Lima, discute, em seu artigo Aprendizagens na era digital: dentro e fora da escola, a necessidade de se "reconhecer e integrar os conhecimentos que são transmitidos nas salas de aula, assim como as experiências, vivências e práticas do estudante fora delas”. A autora afirma que "a educação não pode estar à margem das inovações sociais e tecnológicas porque os processos do aprender estão sendo afetados pelas relações que os mais jovens tecem com os meios de comunicação". 


\section{GESTÃO DA COMUNICAÇÃO}

$\mathrm{O}$ artigo A Educomunicação e o POIE: possíveis aproximações, de autoria de Michele Marques Pereira, especialista em Educomunicação pela Escola de Comunicação e Artes da Universidade de São Paulo, trata da "relação entre o trabalho, orientações curriculares e diretrizes normativas para o professor orientador de Informática Educativa - POIE - e os princípios e práticas educomunicativas". A autora analisa a função deste professor, conforme regulamenta a Secretaria Municipal de Ensino da cidade de São Paulo, em relação aos preceitos e práticas educomunicativas.

\section{ENTREVISTA}

O professor Richard Romancini entrevista os pesquisadores Colin Lankshear e Michele Knobel, conhecidos no Brasil pelo livro Pesquisa Pedagógica: do projeto à implementação. O casal é especialista no estudo dos "novos letramentos", nomenclatura que dão "a série de práticas contemporâneas ligadas às tecnologias digitais, particularmente, os blogs, wikis e redes sociais”. Os pesquisadores apresentam os objetivos e os interesses que têm pela temática dos "novos letramentos" e discutem suas preocupações com a "aprendizagem social", chamando nossa atenção sobre como ela pode relacionar-se com a educação formal e com as novas mídias.

\section{CRÍTICA}

Em Imprensa e discurso histórico: a Comissão Nacional da Verdade na Folha de S.Paulo $e$ no Estado de S. Paulo, os autores Felipe Correa de Mello e Maria Aparecida Baccega discutem alguns "apontamentos acerca da presença do discurso histórico na imprensa a partir da cobertura do relatório final da Comissão Nacional da Verdade", realizados pelos jornais acima citados. Os autores têm por objetivo compreender a produção de sentidos veiculados por meio da cobertura da Comissão da Verdade, e, assim, "apontar o caráter conflitivo na abordagem da memória coletiva e na escrita da história - dimensão fundamental para a construção de uma cultura verdadeiramente democrática”.

\section{DEPOIMENTO}

Jussara Mangini, jornalista, especialista em Gestão da Comunicação, e assistente da Gerência de Comunicação da Fapesp, faz, em seu artigo, depoimento sobre os aprendizados em sua carreira como profissional de divulgação de Ciência em diferentes instituições públicas. Em sua trajetória, destaca a preocupação de muitos especialistas em relação ao pouco espaço que a grande imprensa fornece para a divulgação científica. Por outro lado, Mangini também 
argumenta sobre a importância da propagação de sites e blogs de Ciência como uma tendência mundial que vem se consolidado e abrindo oportunidades de atuação profissional e de ampliação de público.

\section{EXPERIÊNCIA}

André Lemos, professor da Faculdade de Comunicação da Universidade Federal da Bahia, relata sua experiência ao aplicar o método de "classe invertida" (Flipped Classroom) na disciplina Comunicação e Tecnologia, para alunos das habilitações de Jornalismo e Produção Cultural. O diálogo e a autonomia no processo de troca entre professor-alunos nortearam as orientações para os trabalhos durante as aulas, cuja dinâmica procurou reduzir as aulas expositivas e incrementar a pesquisa, o debate e a produção de textos pelos alunos. As potencialidades de acesso à informação pelas novas tecnologias de comunicação foram os pressupostos para a execução da experiência.

\section{POESIA}

Murilo Mendes é o poeta escolhido nesta edição. O professor Citelli destaca um período em que, na produção do autor, aparecem poemas de tom irônico, sarcásticos, com linguagem provocativa, a exemplo de Canção do exílio e Família russa no Brasil. Poemas de tom político são escritos antes da Segunda Guerra e publicados nos livros Metamorfose, Mundo enigma e Poesia Liberdade. Para Citelli "as experiências poéticas de Murilo Mendes, tanto no plano formal como de temas e conteúdos, alcançam amplitude nos registros provocadores que se desdobram em diálogos com o cubismo, os procedimentos futuristas de montagem e mesmo os exercícios com elementos oníricos explorados à larga pelo surrealismo".

\section{RESENHAS}

A resenha Torre de Marfim - Um panorama sobre a mercantilização do ensino superior nos Estados Unidos, de autoria de Katya Zuquim Braghini. O filme trata do "processo de meio século de desmantelamento das linhas de subsídio público aos estudantes do ensino superior nos Estados Unidos e o paulatino aumento dos financiamentos privados que acabam por transformar os recém-formados em devedores antes mesmo de seres trabalhadores". O artigo de Ligia Maria Prezia Lemos, Produção transmídia e ficção televisiva ibero-americana, resenha o livro Anuário Obitel 2014: Estratégias de Produção Transmídia na Ficção Televisiva, cujos coordenadores são Maria Immacolata Vassallo de Lopes e Guillermo Orozco Gómez. A autora destaca a importância da publicação, sobretudo, pela análise que realiza das estratégias da produção transmídia e a importante metodologia de classificação e análise dessas 
estratégias. Maria Ignês Carlos Magno, em Esse Mundo É Dos Loucos e Azyllo Muito Louco. Razão e desrazão em tempos sombrios, trata de dois filmes cujo tema central é a loucura, "mais propriamente, a tênue linha que separa a loucura da sanidade". A ideia é a de mostrar como os cineastas se "utilizam da ficção para provocar reflexões sobre tempos e acontecimentos históricos”.

\section{ATIVIDADES EM SALA DE AULA}

Ruth Itacarambi Leão sugere ao professor(a) mais um projeto a ser desenvolvido em sala de aula com os artigos deste número de Comunicação $\mathcal{E}$ Educação. A autora, com sua vasta contribuição de mais de quinze anos de projetos formulados e publicados nesta revista, é um exemplo de criatividade do profissional da educação.

\section{REFERÊNCIAS}

BACCEGA, Maria Aparecida. Do mundo editado à construção do mundo. Comunicação \& Educação, São Paulo: Moderna, n. 1, p. 7 -14, set. 1994.

BUBER, Martin. Eu e Tu. São Paulo: Cortez e Moraes, 1977.

FREIRE, Paulo. Extensão ou comunicação. Rio de Janeiro: Paz e Terra, 1971. Educação como prática de liberdade. Rio de Janeiro: Paz e Terra, 1971. Pedagogia do oprimido. Rio de Janeiro: Paz e Terra, 1977.

LIMA, Venício A. Comunicação e cultura. As ideias de Paulo Freire. 2.ed. rev., Brasília: UnB/Perseu Abramo, 2011.

PAGE, Joseph. The revolution that never was: northeast Brazil 1955-1964. Nova York: Grossman, 1972. Apud LIMA, Venício A. Comunicação e cultura. As ideias de Paulo Freire. 2.ed. rev., Brasília: UnB/Perseu Abramo, 2011. 